\title{
SISTEM INFORMASI $U$-ACTIVE PADA SMK AL-KAHFI BERBASIS WEB UNTUK MENGEVALUASI KETERCAPAIAN KURIKULUM SETIAP GURU
}

\author{
Absorihim ${ }^{1)}$, Nawassyarif ${ }^{2)^{*}}$, Yana Kharisma ${ }^{3)}$ \\ 1) Mahasiswa Informatika Universitas Teknologi Sumbawa \\ 2), 3) Dosen Informatika Universitas Teknologi Sumbawa \\ nawassyarif@uts.ac.id ${ }^{2)}$, cancercrow@ gmail.com ${ }^{1)}$, yana.karisma@ uts.ac.id ${ }^{3)}$
}

\begin{abstract}
Abstrak
SMK Al-Kahfi merupakan sekolah yang berbasis pesantren yang diharapkan menjadi salah satu sekolah percontohan sekaligus tuntunan dan kebutuhan masyarakat, namun pada SMK Al-Kahfi proses pengajaran masih terbilang umum, dengan cara guru datang dan mengisi absensi kehadiran kemudian mulai mengajar sesuai jadwal, dan ketika waktu mengajar telah habis, maka guru dipersilahkan untuk pulang. Bersadarkan proses tersebut stakeholders sekolah merasa sulit untuk melihat ketercapaian kurikulum. Maka dari itu dibutuhkan sebuah sistem informasi untuk mengevaluasi ketercapaian kurikulum setiap pengajar. Penelitian ini bertujuan untuk membangun sebuah sistem informasi ketercapaian kurikulum setiap pengajar berbasis web. Dimana sistem ini dikembangkan menggunakan bahasa pemrograman $P H P$ dengan menggunakan MySQL sebagai database. Metode pengembangan perangkat lunak menggunakan metode Waterfall. Pengujian perangkat lunak dilakukan melalui pengujian black-box, Teknik pengumpulan data pada penelitian ini menggunakan observasi, wawancara, dan studi pustaka. Hasil akhir yang di peroleh dari sebuah sistem informasi ketercapaian kurikulum setiap pengajar berbasis web yang mampu memberikan kemudahan dalam melakukan proses evaluasi ketercapaian kurikulum setiap guru.
\end{abstract}

Kata Kunci: U-Active, Sistem Informasi, Kurikulum, Waterfall

\begin{abstract}
Al-Kahfi Vocational School is the pesantren based school which is expected to become one of the pilot schools as well as the guidance and needs of the community, but in Al-Kahfi Vocational teaching process is still fairly common, by the way the teacher comes and fills in attendance then starts teaching according to schedule, and when the teaching time is up, the teacher is welcome to go home. Based on this process, school stakeholders find it difficult to see curriculum achievements. Therefore an information system is needed to evaluate the curriculum achievements of each teacher. This study aims to build an information system for curriculum achievement of each web-based instructor. Where this system was developed using the PHP programming language by using MySQL as a database. The software development method uses the Waterfall method. Software testing is done through black-box testing, data collection techniques in this study using observation, interviews, and literature study. The final result obtained is an information system on the achievement of the curriculum of each web-based instructor who is able to provide convenience in evaluating the curriculum achievement of each teacher.
\end{abstract}

Keywords: U-Active, Information System, Curriculum, Waterfall

\section{Pendahuluan}

Pendidikan merupakan suatu pembelajaran yang dilakukan guna memperoleh ilmu pengetahuan dan keterampilan, yang didapatkan melalui sekolah. Dengan harapan dapat menciptakan sumber daya yang berkualitas dan bermanfaat. Maka dari itu sekolah harus menjadi tempat yang baik demi terciptanya proses pembelajaran, agar mudah untuk memberikan ilmu pengetahuan kepada peserta didik, sehingga lulusan dari sekolah tersebut dapat bersaing secara kompetitif.
Salah satu langkah dari pemerintah guna menciptakan lulusan yang berkualitas adalah dengan merubah proses belajar mengajar dari Kurikulum Tingkat Satuan Pendidikan (KTSP) menjadi Kurikulum 2013 (K13). Karena K13 lebih revolusioner, lebih bisa mengakomodir aspek-aspek yang luput pada kurikulum sebelumnya, secara umum K13 memiliki 4 aspek penilaian, yaitu aspek pengetahuan, aspek keterampilan, aspek sikap, dan perilaku. Maka dari itu penulis ingin mengetahui sejauh mana tingkat implementasi kurikulum yang dimaksud untuk meningkatkan kualitas lulusan peserta didik. 
Pada SMK Al-Kahfi pengajaran masih terbilang umum, karena guru datang dan mengisi absensi kehadiran lalu mulai mengajar sesuai jadwal, ketika waktu habis pembelajaranpun selesai dan pulang, begitupun seterusnya hingga semester berganti. Dari rutinitas tersebut, stakeholders sekolah merasa sulit untuk melihat ketercapaian materi terhadap peserta didik. Permasalahan ini diperburuk karena tidak adanya laporan yang membuat wakil kepala kurikulum sulit untuk mengevaluasi kinerja setiap guru. Berangkat dari permasalahan tersebut, penulis berusaha mencari ide solutif untuk menyelesaikan masalah tersebut. Dengan membangun sistem informasi yang berbasis web agar memudahkan wakil kepala kurikulum SMK Al-Kahfi mengevaluasi kinerja guru. Sistem informasi yang penulis rancang ini dinamakan $U$-Active yang artinya ustadz ustadzah active.

Harapannya setelah adanya sistem informasi $U$-Active ini dapat menjadikan tolak ukur untuk menciptakan peserta didik yang berkualitas dan menjadikan referensi untuk sistem pembelajaran yang telah terlaksana guna dijadikan bahan evaluasi dan indikator lanjutan untuk menargetkan pembelajaran berikutnya.

\section{Tinjauan Pusataka}

Merujuk kepada penelitian yang dilakukan sebeulumnya dengan judul "Sistem Informasi Penilaian Pencapaian Kompetensi Peserta Didik SMK Kurikulum 2013 Berbasis Web PHP" Studi kasusnya di SMK Pangudi Luhur Muntilan, dan permasalahan yang ditemukan pada penelitiannya adalah terlalu lamanya proses penginputan nilai raport dari peserta didik sehingga banyak waktu dan tenaga yang terbuang. Penelitiannya bertujuan untuk membantu tim kurikulum dalam mengumpulkan dan merekap nilai dari guru mata pelajaran serta memberikan informasi pengelolaan nilai yang berguna untuk pihak sekolah. [1].

Dari penelitian yang dilakukan, memiliki persamaan dan perbedaan dengan penelitian yang akan dibuat oleh penulis, persamaannya yaitu dapat memberikan sistem dan informasi untuk membantu pengerjaan agar lebih efektif dan efisien, bahkan perbedaannya yaitu sistem yang dibuat hanya menggunakan data dari nilai setiap mata pelajaran, sedangkan sistem yang akan dibuat peneliti menggunakan data dari silabus setiap guru. untuk keunggulan yang diberikan dari sistem informasi yang dibuat penulis adalah interface yang sederhana agar mudah untuk dilihat dan display yang tidak membingungkan sehingga efektif dan efisien ketika digunakan.

Penelitian selanjutnya yang sudah dilakukan dengan judul "Analisis dan Pengembangan Sistem Informasi Penilaian Kinerja Guru Berbasis Web di SMK Negeri 2 Yogyakarta. Dan permasalahan yang ditemukan dalam penelitiannya adalah sulitnya mengarsipkan data kinerja guru yang jumlah filenya semakin tahun semakin bertambah. Penelitiannya bertujuan untuk dapat membantu mengetahui tingkat validitas, kepraktisan, dan reabilitas penilaian kinerja guru, mudah mengarsipkan data penilaian kinerja guru. Sehingga untuk kesimpulan dari penelitiannya adalah Sistem Informasi Penilaian Kinerja Guru dikembangkan dengan menggunakan model pengembangan Rational Unified Process (RUP) yang terdiri dari 4 tahap yaitu : Inception, Elaboration, Counstruction, dan Transition. [2].

Dari penelitian yang dilakukan memiliki persamaan dan perbedaan dengan penelitian yang dilakukan oleh penulis, persamaannya yaitu dapat memberikan sistem dan informasi untuk membantu pengerjaan agar lebih efektif dan efisien, bahkan perbedaannya, penelitian yang telah dilakukan menggunakan model pengembangan RUP sedangkan model pengembangan yang dilakukan oleh penulis adalah model waterfall. keunggulan yang diberikan dari sistem informasi yang dibuat penulis adalah interface yang sederhana agar mudah untuk digunakan dan display yang tidak membingungkan sehingga efektif dan efisien ketika digunakan.

Sistem adalah serangkaian prosedur yang saling berhubungan untuk mencapai tujuan yang sudah direncanakan. [3].

Peneliti lain mengatakan Sistem adalah jaringan yang sudah berisi prosedur dengan pola terpadu untuk mencapai suatu tujuan. [4].

Jadi sistem adalah sekumpulan prosedur yang berisikan perintah-perintah tersusun sehingga dapat memberikan informasi akurat.

Informasi adalah sebuah data yang telah diolah oleh sistem yang berguna dan bermanfaat bagi pengguna. [5].

Menurut peneliti lain informasi adalah sebuah data yang terorganisir sehingga dapat memberikan arti kepada pengguna. [6].

Jadi dari penjelasan informasi yang telah diuraikan bahwa informasi adalah kumpulan data yang telah dikelola sehingga menjadi sebuah arti yang berguna dan manfaat.

Sistem informasi adalah serangkaian perintah formal dimana data dikelompokkan dan diproses menjadi informasi agar dapat didistribusikan. [7].

\section{METODOLOGI PENELITIAN}

Dalam mengumpulkan data penelitian, peneliti menggunakan metode penelitian kualitatif. [8].

\section{Metode Pengumpulan Data}

Metode pengumpulan data merupakan teknik atau cara untuk memperoleh data yang dibutuhkan dalam proses penelitian. Dalam hal ini, penulis menggunakan pendekatan kualitatif deskriptif. Adapun teknik dalam pengumpulan data yaitu :

1. Observasi 
Pada tahapan awal pengumpulan data penulis melakukan observasi ke tempat penelitian yaitu SMK AL-KAHFI untuk melakukan pengamatan secara langsung mengenai kurikulum saat ini, sehingga dapat diketahui alur prosesnya.

2. Wawancara

Tahapan pengumpulan data ini penulis melakukan wawancara langsung dengan Ibu Jasmawati selaku Wakasek bagian Kurikulum SMK AL-KAHFI untuk dapat bertukar informasi mengenai permasalahan yang terjadi, mengumpulkan data-data dan membahas serta merancang bangun sistem informasi yang akan dibuat.

\section{Studi Pustaka}

Pada tahapan pengumpulan data ini penulis memperoleh data dari mempelajari konsep, teknik, maupun informasi dari berbagai sumber seperti internet, buku, jurnal, maupun artikel ilmiah lainnya yang berkaitan dengan merancang bangun sistem informasi yang akan dibuat.

\section{Metode Pengembangan Perangkat Lunak}

Adapun tahapan-tahapan pengembangan perangkat lunaknya yaitu. [9] :

a. Analisa Kebutuhan

Tahap awal yang dilakukan oleh penulis dalam mengembangkan sistem yang sedang berjalan. Selain menganalisa sistem yang sedang berjalan penulis juga menganalisa kebutuhan perangkat keras, perangkat lunak, kebutuhan pengguna serta kebutuhan data yang akan digunakan.

b. Desain Sistem

Setelah melewati tahap analisa kebutuhan selanjutnya masuk pada tahap desain sistem yaitu dimana penulis akan melakukan perancangan alur aplikasi atau sistem yang akan dibangun.

c. Penulisan Kode Program

Pada tahap ini merupakan proses pembuatan aplikasi atau sistem yang sesuai dengan apa yang telah dilakukan pada tahap perencanaan, analisa dan desain sistem. Yang kemudian dilakukan penulisan kode program.

d. Pengujian Program

Tahap ini merupakan tahap pengujian dan tahap pendukung yang artinya aplikasi atau sistem yang telah dibuat atau dibangun dari hasil analisis masalah yang telah melalui tahapan analisa, desain sistem, penulisan kode program barulah kemudian masuk kedalam proses pengujian program , sehingga akan dapat diketahui seperti apa hasil kerja dari aplikasi tersebut, kemudian akan diketahui pula apakah aplikasi yang telah dibuat berjalan baik sesuai dengan apa yang diharapkan.

e. Implementasi

Pada tahap ini dilakukan proses penerapan aplikasi yang telah selesai di buat pada tempat penelitian untuk mengganti sistem yang sebelumnya

\section{Alat dan Bahan Penelitian}

Adapun alat dan bahan yang dibutuhkan dalam penelitian yaitu, kebutuhan perangkat dan kebutuhan data. Kebutuhan perangkat yang digunakan berupa perangkat keras (hardware), perangkat lunak (software), dan kebutuhan pengguna (user) dengan hak aksesnya sesuai dengan kebutuhan penelitian yang dilakukan. Sedangkan untuk kebutuhan data yang digunakan berupa data-data yang berkaitan dengan penelitian yang dilakukan.

\section{HASIL DAN PEMBAHASAN}

\section{Perancanan Sistem}

\section{a. Data Flow Diagram \\ 1) Diagram Konteks}

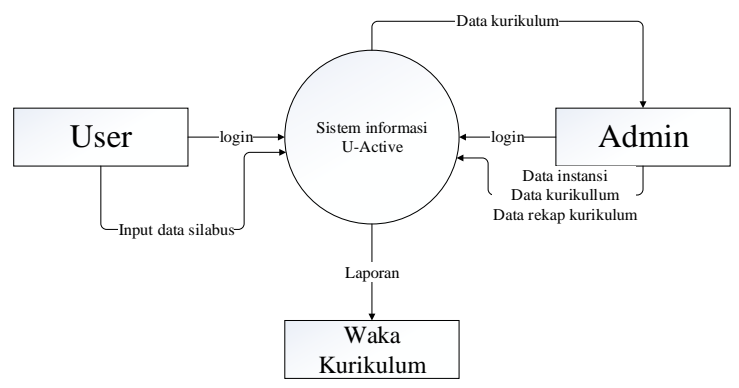

\section{b. Data Flow Diagram Level 0}

Data Flow Diagram merupakan tahapan perancangan dari web yang menggambarkan aliran data dan informasi dalam sebuah sistem. Penggambaran Data Flow Diagram menyatakan dari mana datangnya informasi dan dikirim kemana informasi tersebut dibutuhkan untuk disimpan dan diakses. Berikut adalah Data Flow Diagram level 0.

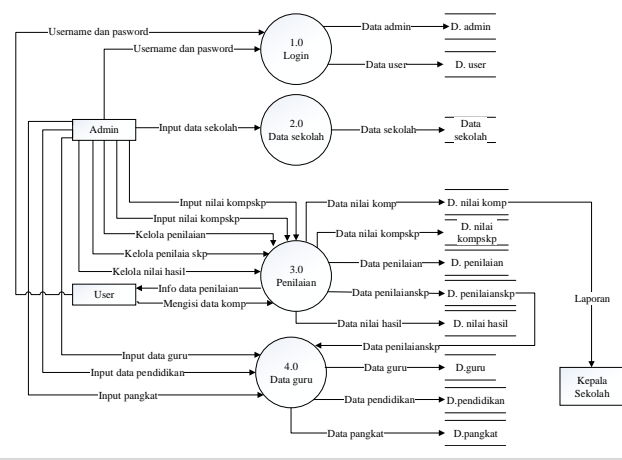




\section{c. DataFlow Diagram Level 1 Proses 1}

Berikut adalah Data Flow Diagram level 1 proses 1.0 dari Sistem Informasi UActive. Admin dan user melakukan login dengan username dan password yang akan tersimpan pada masing-masing datanya

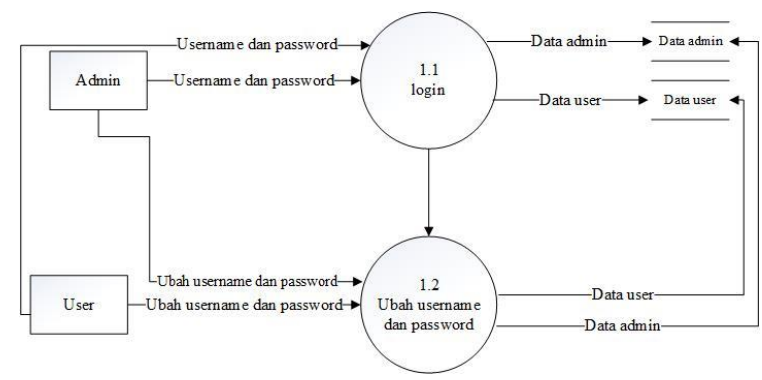

\section{d. Data flow diagram level 1 proses 2}

Pada proses ini dimana admin dapat melakukan perubahan data sekolah seperti : tambah data, ubah data dan hapus data. Berikut adalah Data Flow Diagram level 1 proses 2.0 dari Sistem Informasi U-Active.

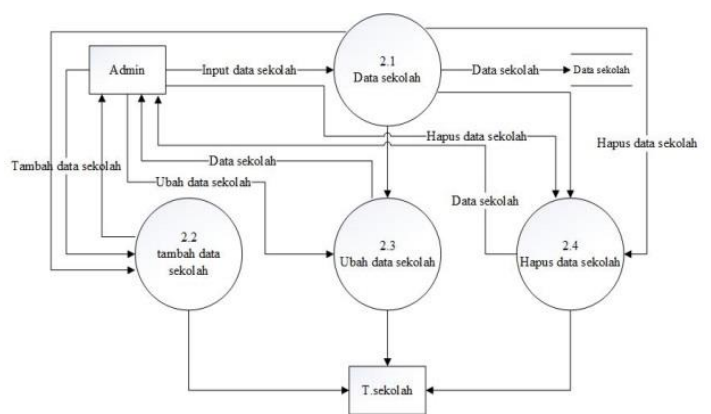

e. Data flow diagram level 1 proses 3

Pada proses ini admin dapat menambahkan data penilaian, mengubah dan menghapus data penilaian seterusnya admin dapat melaporkan hasil data penilaian kepada waka kurikulum. Berikut adalah Data Flow Diagram level 1 proses 3.0 dari Sistem Informasi U-Active.

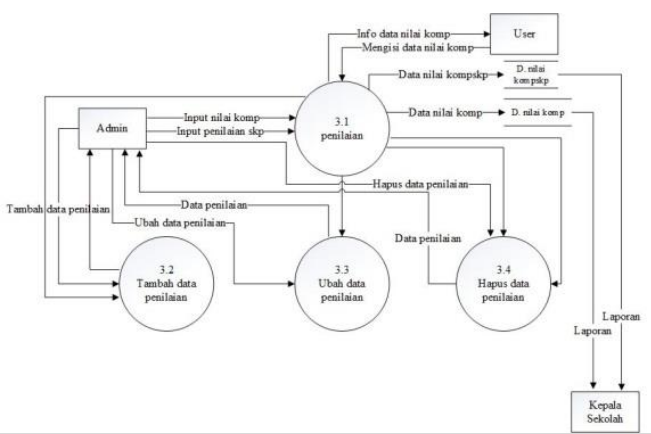

\section{f. Data flow diagram level 1 proses 4}

Berikut adalah Data Flow Diagram level 1 proses 4.0 dari Sistem Informasi UActive yang dimana admin dapat mengolah data guru seperti, tambah data, ubah data dan melihat data guru yang tersimpan dalam database. User hanya bisa mengubah data guru.

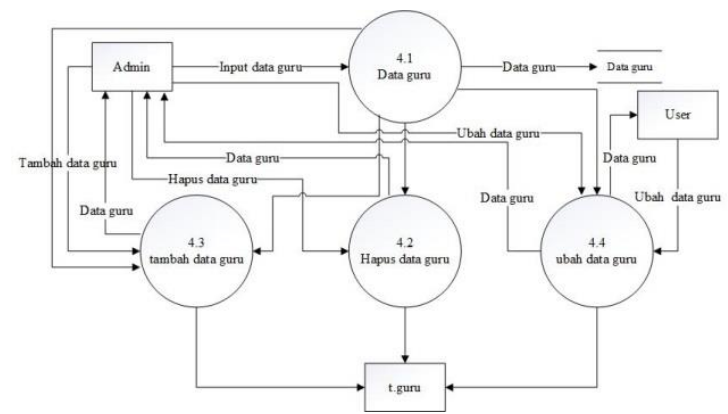

\subsubsection{Entity Relationship Diagram (ERD)}

Entity Relationship Diagram digunakan untuk melihat hubungan antara entitas yang terdapat dalam Sistem Informasi U-Active. Baru.Berikut adalah ERD yang terdapat dalam sistem Informasi U-Active

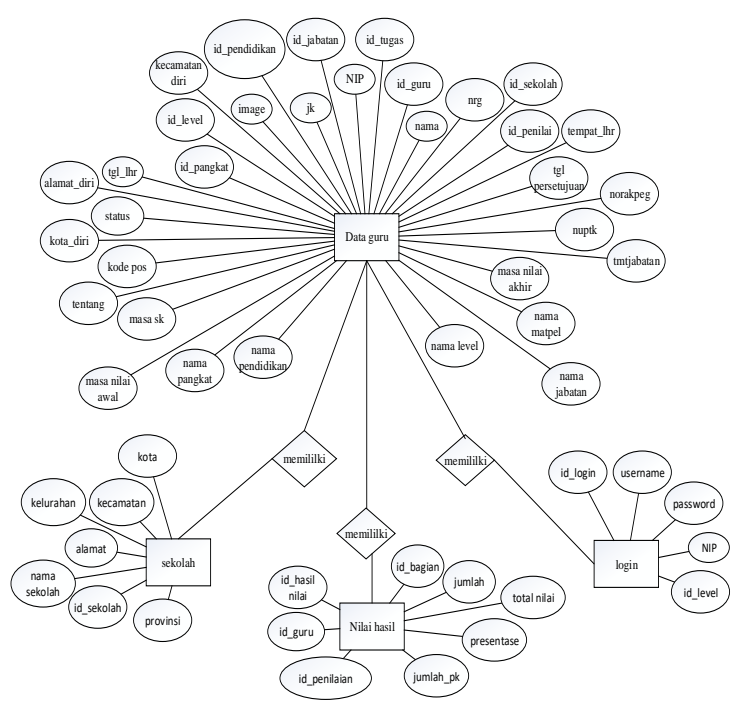

\subsection{Rancangan User Interface}

Rancangan user interface merupakan gambaran rancangan tampilan dari sistem yang akan dibangun. Berikut ini penjabaran tentang rancangan userinterface dari Sistem Informasi UActive. 


\subsubsection{Rancangan Tampilan Dashboard}

Berikut adalah rancangan tampilan awal setelah user atau admin looin tamnilan tersehut adalah dashhoard

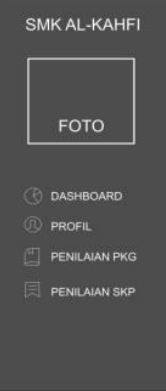

Dari rancangan tampilan diatas terdapat beberapa konten seperti : tampilan foto, tampilan jumlah guru, tampilan jumlah penilai dan dibawah foto profil terdapat konten dashboard, profil, penilaian PKG, dan penilaian SKP serta logout yang berada di atas kanan.

\subsubsection{Rancangan Tampilan Profil}

Berikut rancangan tampilan profil.Tampilan profil pada sistem informasi U-active.

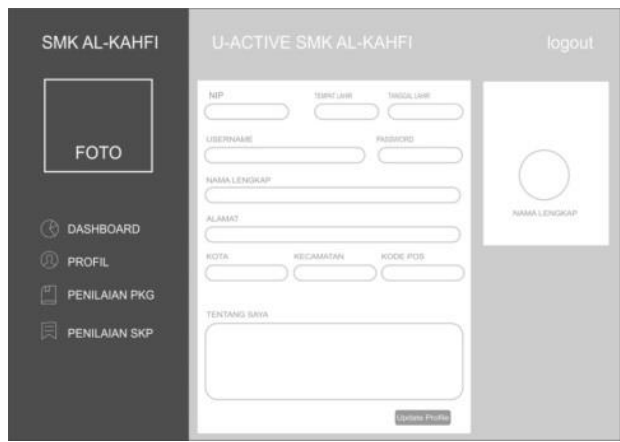

Gambar diatas merupakan rancangan tampilan profil baik untuk admin maupun user kedua dapat merubah datanya sendiri meliputi form NIP, tempat lahir, tanggal lahir, username, password, nama lengkap, alamat, kota, kecamatan, kode pos, tentang saya dan paling bawah adalah button update profil. Serta terdapat foto dan nama pada sisi kanan dan button logout pada bagaian kanan atas.

\subsubsection{Rancangan Tampilan Data Sekolah}

Berikut adalah tampilan untuk data sekolah

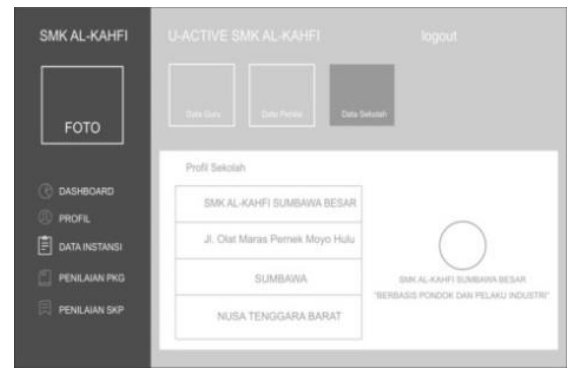

\subsection{Implementasi User Interface \\ 4.4.1 Tampilan utama}

Tampilan dibawah ini merupakan hasil implementasi dari halaman utama sistem informasi U-Active pada SMK Alkahfi.

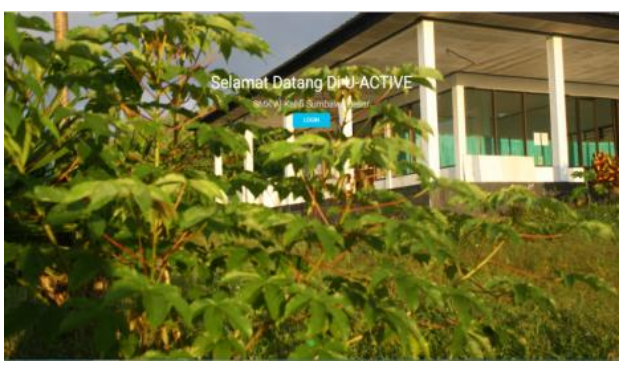

Mengambil gambar pemandangan rumput dan bangunan masjid, karena SMK Al-kahfi berbasis pondok. Rumput merupakan kesegaran dan kenyamanan sehingga santri sekolah tersebut bisa belajar dengan tenang.

4.4.2 Tampilan Input Username dan Password

Tampilan dibawah ini merupakan implementasi dari halaman input username dan password dari sistem informasi UActive pada SMK Al-kahfi.

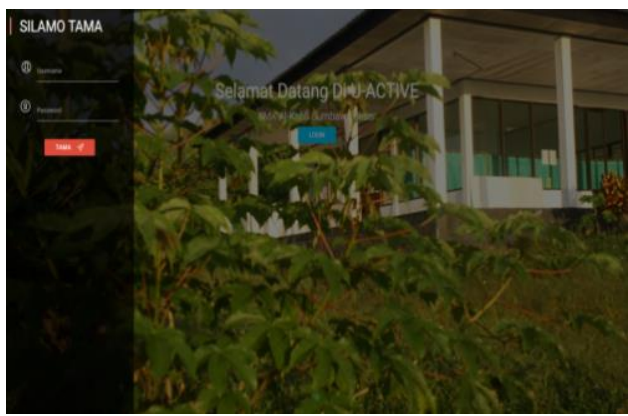

Tampilan dari gambar 4.22 diatas peneliti mengambil warna sedikit gelap dibagian sebelah kiri dan button tama mengambil warna orange karna mengambil dari warna logo SMK Al-kahfi.

\subsubsection{Tampilan Penilaian PKG}

Adapun tampilan dari halaman penilaian PKG dari sistem informasi UActive adalah sebagai berikut.

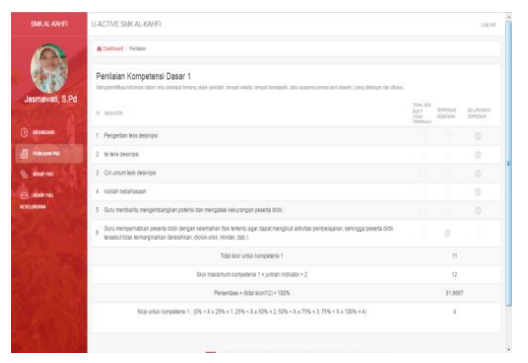


Tampilan gambar diatas merupakan tampilan pada penilaian PKG masih menggunakan warna yang konsisten putih dan merah. Terdapat form untuk mengisi indicator dari kompetensi dasar..

\subsubsection{Tampilan Data Penilai}

Tampilan dibawah ini merupakan halaman penilai dari sistem informasi UActive pada SMK Al-kahfi yang terdapat pada bagian isntansi. Tampilan data penilai adalah sebagai berikut.
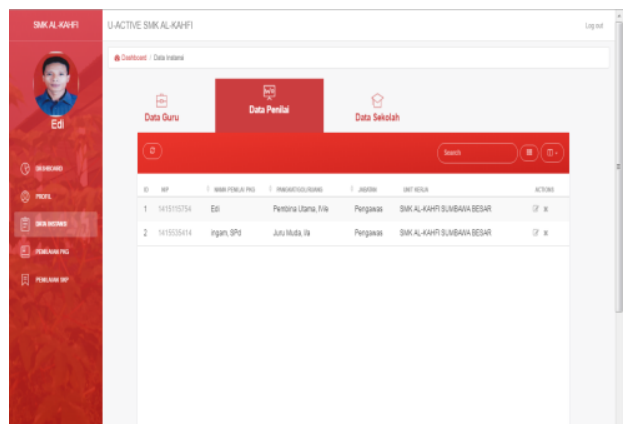

Gambar diatas merupakan tampilan dari data penilai yang hanya menginformasikan data penilai saja. Menggunakan warna putih sebagai latar belakangnya.

\subsection{Pengujian Sistem}

Dalam pengujian ini dilakukan dengan metode black box yaitu pengetesan secara fungsional terhadap perangkat lunak yang terfokus pada input dan output untuk menentukan keberhasilan yang sudah.

\begin{tabular}{|c|l|l|l|l|}
\hline No & Pengujian & Tujuan & Indikator & $\begin{array}{c}\text { Hasil } \\
\text { Pengujian }\end{array}$ \\
\hline 1 & $\begin{array}{l}\text { Pengujian } \\
\text { Login }\end{array}$ & $\begin{array}{l}\text { Mengec } \\
\text { ek } \\
\text { proses } \\
\text { menu } \\
\text { login }\end{array}$ & $\begin{array}{l}\text { Masuk ke } \\
\text { halaman } \\
\text { dashboard }\end{array}$ & Berhasil \\
\hline 2 & $\begin{array}{l}\text { Pengujian } \\
\text { halaman } \\
\text { profil }\end{array}$ & $\begin{array}{l}\text { Mengec } \\
\text { ek } \\
\text { keberha } \\
\text { silan } \\
\text { data } \\
\text { profil }\end{array}$ & $\begin{array}{l}\text { Edit profil } \\
\text { dapat } \\
\text { dilakukan } \\
\text { oleh } \\
\text { admin dan } \\
\text { user. }\end{array}$ & Berhasil \\
\hline 3 & $\begin{array}{l}\text { Menambah } \\
\text { data guru }\end{array}$ & $\begin{array}{l}\text { Mengec } \\
\text { ek } \\
\text { apakah } \\
\text { data } \\
\text { guru } \\
\text { bertamb } \\
\text { ah atau } \\
\text { tidak }\end{array}$ & $\begin{array}{l}\text { Jika data } \\
\text { guru dapat } \\
\text { bertambah } \\
\text { artinya } \\
\text { penambah } \\
\text { an data } \\
\text { berhasil, } \\
\text { maka data } \\
\text { guru akan } \\
\text { tersimpan }\end{array}$ & Berhasil \\
\hline
\end{tabular}

\begin{tabular}{|c|c|c|c|c|}
\hline & & & $\begin{array}{l}\text { dan } \\
\text { berubah } \\
\text { dari } \\
\text { sebelumn } \\
\text { ya. }\end{array}$ & \\
\hline 4 & $\begin{array}{l}\text { Hapus data } \\
\text { guru }\end{array}$ & $\begin{array}{l}\text { Mengec } \\
\text { ek } \\
\text { apakah } \\
\text { data } \\
\text { guru } \\
\text { dapat } \\
\text { terhapus } \\
\text { atau } \\
\text { tidak }\end{array}$ & $\begin{array}{l}\text { Menampil } \\
\text { kan } \\
\text { warning } \\
\text { apakah } \\
\text { data } \\
\text { benar- } \\
\text { benar } \\
\text { akan } \\
\text { dihapus, } \\
\text { jika telah } \\
\text { dihapus } \\
\text { maka data } \\
\text { akan } \\
\text { terhapus } \\
\text { dari daftar } \\
\text { guru. }\end{array}$ & Berhasil \\
\hline 5 & $\begin{array}{l}\text { Pengujian } \\
\text { untuk } \\
\text { menghitun } \\
\mathrm{g} \\
\text { kompetensi } \\
\text { yang } \\
\text { terlaksana }\end{array}$ & $\begin{array}{l}\text { Mengec } \\
\text { ek } \\
\text { apakah } \\
\text { hitunga } \\
\text { n } \\
\text { presenta } \\
\text { se } \\
\text { sesuai } \\
\text { atau } \\
\text { tidak }\end{array}$ & $\begin{array}{l}\text { Untuk } \\
\text { dapat } \\
\text { menghitun } \\
\text { g } \\
\text { ketercapai } \\
\text { an } \\
\text { kopetensi } \\
\text { dasar }\end{array}$ & Berhasil \\
\hline 6 & $\begin{array}{l}\text { Pengujian } \\
\text { log out } \\
\text { atau keluar }\end{array}$ & $\begin{array}{l}\text { Mengec } \\
\text { ek } \\
\text { proses } \\
\text { keluar } \\
\text { sistem }\end{array}$ & $\begin{array}{l}\text { Dapat } \\
\text { keluar dari } \\
\text { sistem }\end{array}$ & Berhasil \\
\hline
\end{tabular}

\section{KESIMPULAN DAN SARAN}

Berdasarkan hasil dari analisis serta perancangan sistem informasi yang telah dilakukan peneliti menarik kesimpulan, yaitu :

1. Rancang bangun sistem informasi U-Active pada SMK Al-kahfi telah selesai dibangun dengan menggunakan metode pengembangan perangkat lunak waterfall dan bahasa pemrograman $P H P$ serta menggunakan database MySQL. Metode pengembangan yang digunakan yaitu metode perancangan terstruktur yang meliputi Data Flow Diagram (DFD) dan Entity Relationship Diagram (ERD).

2. Menghasilkan sistem informasi yang mudah diakses oleh user, seperti : nilai ketercapaian, data guru, dan data PKG.

Adapun saran terhadap sistem ini untuk perbaikan atau pengembangan selanjutnya sebagai berikut : 
1. Halaman Dashboard agar terisi banyak informasi.

2. Perhitungan untuk ketercapaian dibuat agar lebih rapih dan menarik.

3. Diharapkan dapat terhubung dengan absensi kehadiran.

4. Diharapkan dapat menghitung nilai standar KKM bagi siswa

\section{DAFTAR PUSTAKA}

[1] Wijayanto, Indra Petrus. 2017. Sistem Informasi PenilaianPencapaian Kompetensi Peserta Didik SMK Kurikulum 2013 Berbasis Web PHP. Yogyakarta. Tanggal Akses 04 Maret 2019

[2]Mukta, Hikam. 2018. Analisis dan Pengembangan Sistem Informasipenilaian Kinerja Guru Berbasis Web di SMK Negeri 2 Yogyakarta. Yogyakarta. Tanggal Akses 04 Maret 2019.

[3] Al-Fatta, Hanif. 2007. Analisis dan Perancangan Sistem Informasi. Yogyakarta: Penerbit Andi.

[4] Sutabri, Tata. 2012. Analisis Sistem Informasi. Yogyakarta: CV Andi Offset.

[5] Hutahean, Japerson. 2015. Konsep Sistem Informasi. Yogyakarta: CV Budi Utama [6] Handoyo, Osie Holy. 2011. Sistem Informasi Penjualan Berbasis Web. Skripsi : Universitas Sanata Dharma.

[6] Mulyani, Sri. 2016 Metode Analisis dan Perancangan Sistem. Bandung: Abdi Sistematika. Mulyani, Sri. 2016 Metode Analisis dan Perancangan Sistem. Bandung: Abdi Sistematika.

[7] Kadir, Abdul. 2013. Pengenalan Sistem Informasi Edisi Revisi. Yogyakarta: Andi Offset.

[8] Sarwono, Jonathan. 2006. Metode Penelitian Kuantitatif dan Kualitatif. Yogyakarta : Graha Ilmu.

[9] Pressman, Roger, S. (2012). Rekayasa Perangkat Lunak Pendekatan Praktisi Edisi 7. Yogyakarta: Andi Offset 